\title{
A Comparison of Upper Tract TCC Treated Conservatively with Boari Flap or Laser Fulguration
}

\section{Simon Robinson*, Butler A, Bhardwa J, Kalsi J and Motiwala H \\ Department of Urology, Frimley health foundation trust, UK}

*Corresponding author: Simon Robinson, Department of Urology, Frimley health foundation trust, wexham lane, East Berkshire, SL24HL, UK, Tel: 01753 633000; Email: simon.robinson@nhs.net

\section{Research Article \\ Volume 4 Issue 4}

Received Date: November 16, 2019

Published Date: December 05, 2019

DOI: $10.23880 /$ ajun- 16000171

\section{Abstract}

We compare two conservative treatments for upper tract urothelial cancer (UTUC), laser fulguration and Boari flap. We review the indications for these treatments and the short (32 months) and long term (144 months) outcomes.

Methods: Retrospective analysis of 20 Boari flap patients and prospectively 13 laser fulguration patients.

Results: There was an all-cause mortality of $10 \%$ for the Boari group and $23 \%$ for the laser group (log rank P 0.19 ) at 32 months. There was $40 \%$ mortality at 144 months for the Boari group.

Conclusion: Oncological control can be effectively obtained with these conservative treatments. There was no significant difference between the two groups in terms of patient or tumour characteristics. The long term follow up for the Boari group can, with circumspection, be extrapolated to the laser group.

Keywords: Laser Fulguration; Boari flap

Abbreviations: UTUC: Upper Tract Urothelial Cancer.

\section{Introduction}

We are investigating whether there is any difference in the population, the tumour characteristics or the outcomes of a small number of patients treated for upper urinary tract TCC treated by two different conservative modalities, laser fulguration, our current practise, and local surgical excision with the Boari flap, our former practise. This conservative treatment is increasingly popular with the correct selection of patients with principally low risk UTUC to give equivalent oncological control when compared with traditional radical treatment, the radical nephro-ureterectomy [1,2].

\section{Epidemiology, Pathology, Prognosis and Treatment}

Urothelial cancer is the fifth most common cancer [3]. Upper tract urothelial cancer UTUC accounts for only 5$10 \%$ of this pelvicalyceal tumours are twice as common as ureteric $[3,4]$. Importantly $60 \%$ are invasive at diagnosis compared to only $20 \%$ of bladder TCC [5,6]. In concordance with this more aggressive stage at presentation, only few tumours of low malignant potential are found in the upper tract $[7,8]$. UTUC have a peak incidence at 70-90 years and are three times as common in men $[9,10]$. The most important risk factor is tobacco exposure which increases the relative risk from 2.5 to $7[11,12]$. UTUC often present after a bladder cancer. 
The most common symptom is haematuria approx $75 \%[13,14]$. Flexible ureteroscopy can visualise and biopsy to determine grade in $90 \%$ cases [15] with a low false negative rate. Conclusive diagnosis is fundamental to the decision making process. Ureteroscopy is also more accurate than CT Urogram and this can influence treatment decisions [16]. Confocal laser endomicroscopy can enhance the diagnostic accuracy [17] and biopsies can be performed with increasing accuracy [18]. Undergrading can occur after biopsy, so intensive follow up is necessary [19]. Prognosis is poor with muscle invasion and tends to be worse than bladder cancer [20]. The five year survival is $<50 \%$ for pT2/3 tumours and $<10 \%$ for pT4 [21-23]. Prognosis depends on many factors

\section{Preoperative Factors}

Sex is no longer an independent factor. Increasing age is associated with a worse disease specific survival although elderly can be cured $[25,26]$. Smoking increases risk for recurrence and mortality after RNU and recurrences within bladder [27-29]. Ureteric and multifocal tumours have a worse prognosis than renal pelvic tumours [23,30-33]. ASA score significantly correlates with cancer specific survival after RNU [34].

\section{Postoperative Factors}

The primary prognostic factors are stage and grade [35-37]. Management for localized disease with sparing of the kidney can be ureteroscopic with holmium, neodymium and thulium lasers [38], percutaneous or via an open surgical approach including the Boari flap. Endoscopic ablation can be used for low risk cancer if laser is available [39] with a flexible ureteroscope and complete tumour resection can be achieved. Close stringent follow up is needed particularly if high grade tumours are ablated. However, there is still a risk of under staging and under grading. Segmental ureteric resection with lymphadenectomy. Distal ureterectomy can be used for low risk tumour if they cannot be removed endoscopically and for high risk tumours when renal preservation is required [40-43].

Further, there is a shorter hospital stay and less loss of renal function with conservative treatment. The role of conservative treatment for low risk tumours has been defined as $<2 \mathrm{~cm}$, single lesion, stage $<\mathrm{T} 2$ and low grade. The EUA recommendations for renal sparing management is Offer this as primary treatment for low risk tumours and two functional kidneys If patient has a solitary kidney or poor renal function providing it does not compromise oncological outcome High risk cancers if distal and in imperative cases such as solitary kidney or impaired renal function.

\section{Methods}

33 patients were treated conservatively for UTUC. This is a retrospective analysis for the Boari cohort and prospective for the laser cohort. Both are within one hospital trust. One surgeon performed the twenty Boari flaps from 2004 to 2015. Two further surgeons performed the thirteen laser fulgurations from 2014 to present. Patient and histological details were obtained from hospital electronic data bases. Statistical analysis was done using graph pad and Kaplan Meier graphs generated with excel. Laser used was a holmium 200um fibre 8$15 \mathrm{~Hz} 8 \mathrm{~W}$ Ureteroscopic follow up for the laser group had a first follow up at a mean of 4 months, then 6 monthly.

\section{Results} $1,2)$.

Patient characteristics (Figure 1, Tables 1-3 \& Graphs

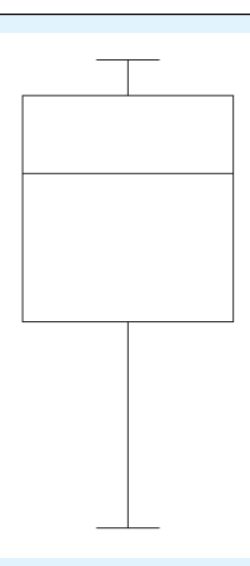

Figure 1: Boari patients, Laser patients. 


\section{Open Access Journal of Urology \& Nephrology}

\begin{tabular}{|c|c|c|c|}
\hline & Boari patients & Laser patients & Significance \\
\hline $\mathrm{N}$ & 20 & 13 & \\
\hline Male/female & $7(35 \%) 13(65 \%)$ & $10(77 \%) 3(23 \%)$ & Fishers $\mathrm{P}=0.032$ \\
\hline Presentation & & & $\mathrm{P}=1.0$ \\
\hline Haematuria & $10(50 \%)$ & $7(54 \%)$ & $\mathrm{P}=1.0$ \\
\hline Surveillance & $5(25 \%)$ & $3(23 \%)$ & $\mathrm{P}=1.0$ \\
\hline Incidental & $5(25 \%)$ & $3(23 \%)$ & \\
\hline Smokers & $13(65 \%)$ & $8(62 \%)$ & \\
\hline ASA score & $5(25 \%)$ & 0 & $\mathrm{P}=0.067$ \\
\hline 1 & $10(50 \%)$ & $5(39 \%)$ & \\
\hline 2 & $15(75 \%)$ & $5(39 \%)$ & $\mathrm{P}=0.067$ \\
\hline ASA 1 and 2 & $5(25 \%)$ & $6(46 \%)$ & $\mathrm{t}$ test $\mathrm{P}=0.076$ \\
\hline 3 & 0 & $2(15 \%)$ & $\mathrm{t}$ test $\mathrm{P}=0.55$ \\
\hline 4 & $5(25 \%)$ & $8(61 \%)$ & $\mathrm{t}$ test $\mathrm{P}=0.29$ \\
\hline ASA 3 and 4 & Mean 71 median 72 & Mean 78.5 median 82 & Mean 111 \\
\hline Age years & Mean 80 & Mean 58 & \\
\hline Creatinine uM & Mean 70 & &
\end{tabular}

Table 1: Box plot age years.

\begin{tabular}{|c|c|c|c|}
\hline & Boari & Laser & \\
\hline Grade & & Not known $2(15 \%)$ & \\
\hline 1 low & $6(30 \%)$ & $2(15 \%)$ & $\mathrm{P}=0.67$ \\
\hline 2 medium & $11(55 \%)$ & $5(39 \%) 2 \mathrm{Hg} 3 \mathrm{Lg}$ & $\mathrm{P}=0.76$ \\
\hline 3 high & $3(15 \%)$ & $4(31 \%)$ & $\mathrm{P}=0.21$ \\
\hline Stage & & Not known $1(7 \%)$ & \\
\hline pTa & $16(80 \%)$ & $11(85 \%)$ & $\mathrm{P}=0.62$ \\
\hline pT1 & $1(5 \%)$ & 0 & $\mathrm{P}=1.0$ \\
\hline pT2 & $3(15 \%)$ & $1(8 \%)$ & $\mathrm{P}=1.0$ \\
\hline Site within ureter & & & $\mathrm{P}=0.002$ \\
\hline Proximal & 0 & $6(46 \%)$ & $\mathrm{P}=0.39$ \\
\hline Mid & 0 & $6(8 \%)$ & $\mathrm{P}=0.002$ \\
\hline Distal & $20(100 \%)$ & 2.2 & $\mathrm{P}=1.0$ \\
\hline Tumour size (mean) cm & 1.5 & 1 & $\mathrm{P}=1.0$ \\
\hline Multifocality & 0 & 1 & $\mathrm{P}=1.0$ \\
\hline Solitary kidney & 0 & $\mathrm{P}=1.0$ \\
\hline Bladder recurrence & 3 patients 3 episodes & 3 patients 5 episodes & $\mathrm{P}=1.0$ \\
\hline Subsequent radical nephro-ureterectomy & 2 & 2 & \\
\hline
\end{tabular}

Table 2: Tumour characteristics.

\begin{tabular}{|c|c|c|c|}
\hline & Boari 144 months & Boari 32 months & Laser 32 months \\
\hline Recurrence & $8(40 \%)$ & $2(10 \%)$ & $8(62 \%)$ \\
\hline Mean time to recurrence & 13 months & 6 months & 4 months \\
\hline Progression & $7(35 \%)$ & 1 & $2(15 \%)$ \\
\hline Mean time to progression & 7.5 months & 6 months & 14 months \\
\hline All cause mortality & $8(40 \%)$ & $2(10 \%)$ & $3(23 \%)$ log rank chi squared $1.69 \mathrm{P}=0.19$ \\
\hline Survived at 32 months & & 17 & 3 \\
\hline Disease specific mortality & $2 / 8(25 \%$ of ACM) & $1(50 \%$ of ACM $)$ & $1 / 3(33 \%$ of ACM $)$ \\
\hline Survival at 32 months & $89 \%$ & $89 \%$ & $64 \%$ \\
\hline
\end{tabular}

Table 3: Prognosis. 


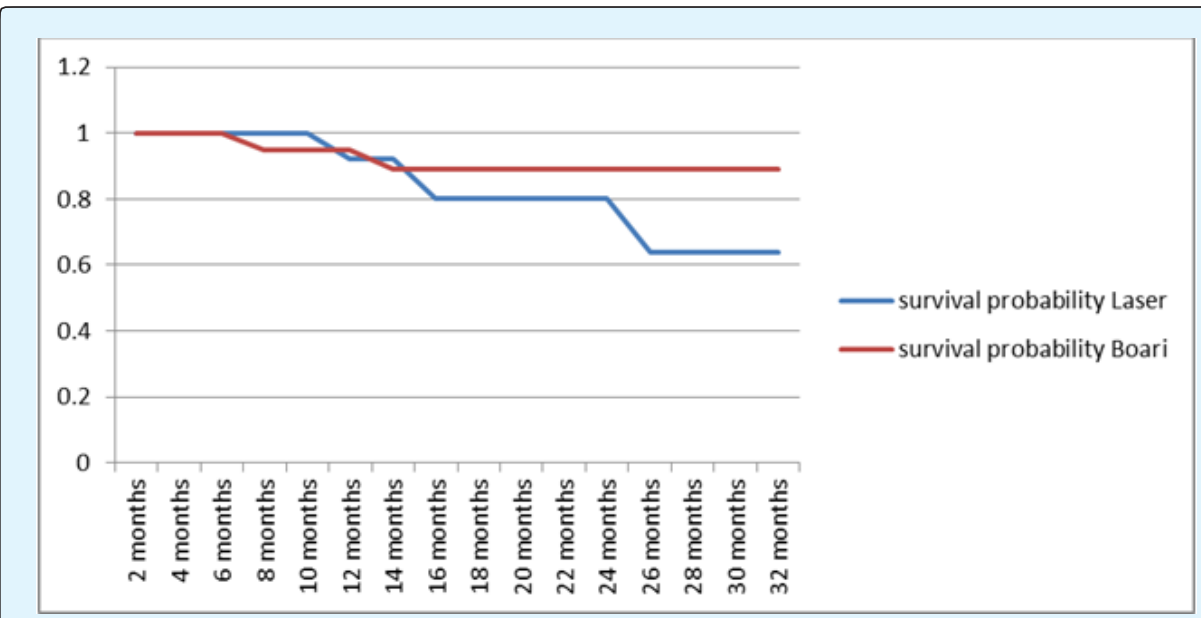

Graph 1: Comparison of overall survival at 32 months.

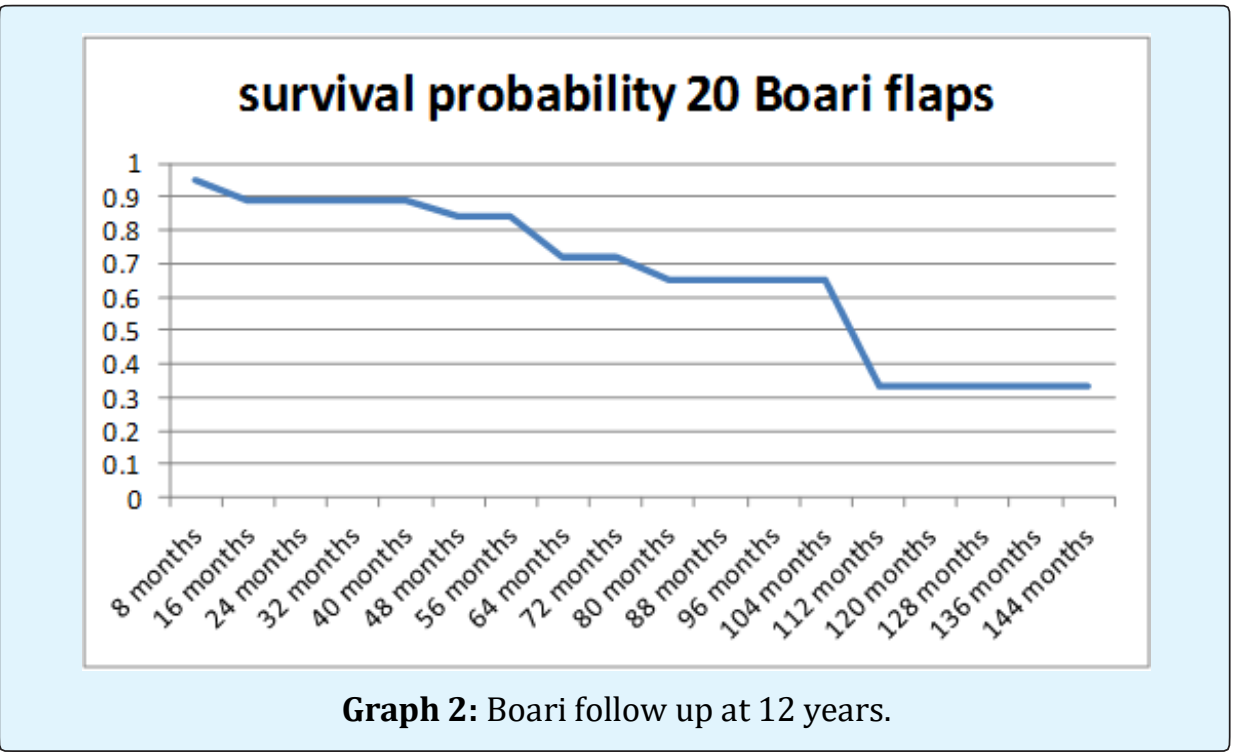

\section{Discussion}

We have a series of 33 patients in total. As there are no significant differences in outcomes or patient/tumour profile so we can accept the survival curve of long-term Boari flap patients as representative of laser patients, albeit with caution. There are indications that have evolved as technology improves specifically with endourology making diagnosis and treatment more efficacious. Our laser population has an equal distribution of proximal and distal tumours (six and six) which is contrary to the trend of proximal dominance. Only three were invasive in the Boari group and one in the laser group, this was probably due to some under staging preoperatively, but the vast majorities on both groups are non-muscle invasive ( $85 \%$ in both groups). The patients tend to be elderly, however, our Boari group was younger with a mean age of 71 compared to 78 in the laser group but this was not significantly different. It is a disease that predominates in men, although our Boari group had more women $(65 \%)$ although sex is no longer recognized as an important independent risk factor.

In both groups, the majorities were or had been smokers (65\% and 62\%). Few PUNLMPs are found in the ureter and indeed these formed the minority in both groups with $30 \%$ in the Boari and $15 \%$ in the laser groups of the eight measured tumour sizes all were small $(<3 \mathrm{~cm})$ and only one was multifocal with two small lesions. Most present as haematuria $50 \%$ and $54 \%$ with the rest being 
diagnosed though bladder screening approx $25 \%$ or incidental findings 25\%. Regarding renal function, there were three patients with impaired renal function. There was no significant difference in either the mean creatinine or glomerular filtration rate between the two groups. One patient within the laser group had a solitary kidney. The ASA scores were summated into two groups, ASA 1 and 2 and ASA 3 and 4. There were more unfit patients in the laser group (61\%) compared to the Boari group (25\%) but this was not significant statistically.

We have treated four high grade patients within the laser group as have others with good outcomes. One of these resulted from upgrading from a G2 biopsy. One patient was upstaged to muscle invasive pT2 disease and underwent radical nephro-ureterectomy two months later, with survival of 13 months so far. Another patient had radical nephro-ureterectomy 10 months later and died 4 months after this operation, 15 months after the original laser procedure. A further patient has died at 26 months post-surgery. The other shows survival at 19 months. Within the Boari group there were three high grade and pT2 stage of which two did not have biopsies. The other was upstaged from pT1 to pT2. They have subsequently died at 15, 49 and 50 months. T3 t4 can be treated in carefully selected pts. Two patients G1pTa and $\mathrm{G} 2 \mathrm{pTa}$ underwent subsequent radical nephroureterectomy dying at 6 and 109 months respectively. $6 / 13$ laser patients had intravesical therapy with 4 having BCG and 2 having MMC. There was no significant difference in bladder recurrence. Looking at all 33 patients and the 11 deaths to summarize the effect of stage on mortality. 8/11 deaths were pTa disease, and $3 / 11$ were pT2. As regards grade, less than half the mortalities were high grade G3, 5/11patients. 3/11 patients were G2 and $3 / 11$ patients were G1. The ASA score was also distributed evenly. $5 / 11$ patients were ASA $3,3 / 11$ patients were ASA 2 and 3/11 patients were ASA 1 . Both methods of treatment were equally efficacious with a long term survival of $65 \%$ at 9 years.

We followed up both groups for 32 months. There were two deaths from all cause in the Boari group and three in the laser. All had ureteric recurrences. Log rank analysis did not show any significant difference $(\mathrm{P}=0.19)$. One death in each group was due to disease progression. We have added the long term follow up the Boari group to illustrate long term survival of $65 \%$ at nine years.

\section{Criticisms}

The number of patients is small. It has a retrospective arm and there may be a selection bias in patients. No comparison with radical nephro-ureterectomy, however we do have a long follow up for Boari arm.

\section{Conclusion}

Good oncological control can be achieved with renal sparing treatments. The newer endoscopic is as efficacious as the Boari flap.

\section{References}

1. Territo A, Foerster B, Shariat SF, Rouprêt M, Gaya JM, et al. (2018) Diagnosis and kidney-sparing treatments for upper tract urothelial carcinoma: state of the art. Minerva Urol Nefrol 70(3): 242-251.

2. Samson P, Smith AD, Hoenig D, Okeke Z (2018) Endoscopic Management of Upper Urinary Tract Urothelial Carcinoma. J Endourol 32(1): 10-16.

3. Siegel RL, Miller KD, Jemal A (2015) Cancer statistics, 2015. CA Cancer J Clin 65(1): 5-29.

4. Munoz JJ, Ellison LM (2000) Upper tract urothelial neoplasms: incidence and survival during the last 2 decades. J Urol 164(5): 1523-1525.

5. Cosentino M, Palou J, Gaya JM, Breda A, RodriguezFaba 0, et al. (2013) Upper urinary tract urothelial cell carcinoma: location as a predictive factor for concomitant bladder carcinoma. World J Urol 31(1): 141-145.

6. Margulis V, Shariat SF, Matin SF, Kamat AM, Zigeuner $\mathrm{R}$, et al. (2009) Outcomes of radical nephroureterectomy: a series from the Upper Tract Urothelial Carcinoma Collaboration. Cancer 115(6): 1224-1233.

7. Olgac S, Mazumdar M, Dalbagni G, Reuter VE (2004) Urothelial carcinoma of the renal pelvis: a clinicopathologic study of 130 cases. Am J Surg Pathol 28(12): 1545-1552.

8. Perez-Montiel D, Wakely PE, Hes O, Michal M, Suster S (2006) High-grade urothelial carcinoma of the renal pelvis: clinicopathologic study of 108 cases with emphasis on unusual morphologic variants. Mod Pathol 19(4): 494-503.

9. Shariat SF, Favaretto RL, Gupta A, Fritsche HM, Matsumoto K, et al. (2011) Gender differences in radical nephroureterectomy for upper tract urothelial carcinoma. World J Urology 29(4): 481-486. 
10. Lughezzani G, Sun M, Perrotte P, Shariat SF, Jeldres C, et al. (2010) Gender-related Differences in Patients With Stage I to III Upper Tract Urothelial Carcinoma: Results From the Surveillance, Epidemiology, and End Results Database. Urology 75(2): 321-327.

11. Crivelli JJ, Xylinas E, Kluth LA, Rieken M, Rink M, et al. (2013) Effect of smoking on outcomes of urothelial carcinoma: a systematic review of the literature. Eur Urol 65(4): 742-754.

12. Toshiaki Shinka, Masahiro Miyai, Yoshihisa Sawada, Takeshi Inagaki, Tadashi Okawa (1995) Factors Affecting the Occurrence of Urothelial Tumors in Dye Workers Exposed to Aromatic Mines. Int J Urology 2(4): 243-248.

13. Inman BA, Tran VT, Fradet Y, Lacombe L (2009) Carcinoma of the upper urinary tract $†$ Predictors of survival and competing causes of mortality. Cancer 115(13): 2853-2862.

14. Nigel C Cowan (2012) CT urography for hematuria. Nature Reviews Urology 9: 218-226.

15. Rojas CP, Castle SM, Llanos CA, Santos Cortes JA, Bird $\mathrm{V}$, et al. (2013) Low biopsy volume in ureteroscopy does not affect tumor biopsy grading in upper tract urothelial carcinoma. Urologic Oncology: Seminars and Original Investigations 31(8): 1696-1700.

16. Gallioli A, Breda A, Boissier R, Territo A, Gaya JM, et al. (2019) The Crucial Role of Ureteroscopy in the Diagnostic/Therapeutic Pathway of Upper Tract Urothelial Carcinoma. Eur Urol Suppl 18(1): 2161.

17. Breda A, Territo A, Guttilla A, Sanguedolce F, Manfredi M, et al. (2018) Correlation Between Confocal Laser Endomicroscopy (Cellvizioß) and Histological Grading of Upper Tract Urothelial Carcinoma: A Step Forward for a Better Selection of Patients Suitable for Conservative Management. Eur Urol Focus 4(6): 954959.

18. Breda A, Territo A, Sanguedolce F, Basile G, Subiela JD, et al. (2018) Comparison of biopsy devices in upper tract urothelial carcinoma. World J Urol 37(9): 18991905.

19. Smith AK, Stephenson AJ, Lane BR, Larson BT, Thomas AA, et al. (2011) Inadequacy of biopsy for diagnosis of upper tract urothelial carcinoma: implications for conservative management. Urology 78(1):82-86.
20. Rouprêt M, Babjuk M, Compérat E, Zigeuner R, Sylvester RJ, et al. (2018) European Association of Urology Guidelines on Upper Urinary Tract Urothelial Carcinoma: 2017 Update. Eur Urol 73(1): 111-122.

21. Abouassaly R, Alibhai SM, Shah N, Timilshina N, Fleshner N, et al. (2010) Troubling outcomes from population-level analysis of surgery for upper tract urothelial carcinoma. Urology 76(4): 895-901.

22. Jeldres C, Sun M, Isbarn H, Lughezzani G, Budäus L, et al. (2010) A population-based assessment of perioperative mortality after nephroureterectomy for upper-tract urothelial carcinoma. Urology 75(2): 315320.

23. Lughezzani G, Burger M, Margulis V, Matin SF, Novara G, et al. (2012) Prognostic factors in upper urinary tract urothelial carcinomas: a comprehensive review of the current literature. Eur Urol 62(1): 100-114.

24. Fernández MI, Shariat SF, Margulis V, Bolenz C, Montorsi F, et al. (2009) Evidence-based sex-related outcomes after radical nephroureterectomy for upper tract urothelial carcinoma: results of large multicenter study. Urology 73(1): 142-146.

25. Shariat SF, Godoy G, Lotan Y, Droller M, Karakiewicz PI, et al. (2010) Advanced patient age is associated with inferior cancer-specific survival after radical nephroureterectomy. BJU Int 105(12): 1672-1677.

26. Chromecki TF, Ehdaie B, Novara G, Pummer K, Zigeuner R, et al. (2011) Chronological age is not an independent predictor of clinical outcomes after radical nephroureterectomy. World J Urol 29(4): 473480.

27. Rink M, Xylinas E, Margulis V, Cha EK, Ehdaie B, et al. (2013) Impact of smoking on oncologic outcomes of upper tract urothelial carcinoma after radical nephroureterectomy. Eur Urol 63(6): 1082-1090.

28. Simsir A, Sarsik B, Cureklibatir I, Sen S, Gunaydin G, et al. (2011) Prognostic factors for upper urinary tract urothelial carcinomas: stage, grade, and smoking status. Int Urol Nephrol 43(4): 1039-1045.

29. Xylinas E, Kluth LA, Rieken M, Lee RK, Elghouayel M, et al. (2014) Impact of smoking status and cumulative exposure on intravesical recurrence of upper tract urothelial carcinoma after radical nephroureterectomy. BJU Int 114(1): 56-61. 
30. Yafi FA, Novara G, Shariat SF, Gupta A, Matsumoto K, et al. (2012) Impact of tumour location versus multifocality in patients with upper tract urothelial carcinoma treated with nephroureterectomy and bladder cuff excision: a homogeneous series without perioperative chemotherapy. BJU Int 110(2 Pt 2): 713.

31. Ouzzane A, Colin P, Xylinas E, Pignot G, Ariane MM, et al. (2011) Ureteral and multifocal tumours have worse prognosis than renal pelvic tumours in urothelial carcinoma of the upper urinary tract treated by nephroureterectomy. Eur Urol 60(6): 1258-1265.

32. Chromecki TF, Cha EK, Fajkovic H, Margulis V, Novara G, et al. (2012) The impact of tumor multifocality on outcomes in patients treated with radical nephroureterectomy. Eur Urol 61(2): 245-253.

33. Williams AK, Kassouf W, Chin J, Rendon R, Jacobsen N, et al. (2013) Multifocality rather than tumor location is a prognostic factor in upper tract urothelial carcinoma. Urol Oncol 31(7): 1161-1165.

34. Berod AA, Colin P, Yates DR, Ouzzane A, Audouin M, et al. (2012) The role of American Society of Anesthesiologists scores in predicting urothelial carcinoma of the upper urinary tract outcome after radical nephroureterectomy: results from a national multi-institutional collaborative study. BJU Int 110(11): 1035-1040.

35. Clements T, Messer JC, Terrell JD, Herman MP, Ng CK, et al. (2012) High-grade ureteroscopic biopsy is associated with advanced pathology of upper-tract urothelial carcinoma tumors at definitive surgical resection. J Endourol 26(4): 398-402.

36. Lehmann J, Suttmann H, Kovac I, Hack M, Kamradt J, et al. (2007) Transitional cell carcinoma of the ureter: prognostic factors influencing progression and survival. Eur Urol 51(5): 1281-1288.
37. Li CC, Chang TH, Wu WJ, Ke HL, Huang SP, et al. (2008) Significant predictive factors for prognosis of primary upper urinary tract cancer after radical nephroureterectomy in Taiwanese patients. Eur Urol 54(5): 1127-1134.

38. Wen J, Ji ZG, Li HZ (2018) Treatment of upper tract urothelial carcinoma with ureteroscopy and thulium laser: a retrospective single center study. BMC Cancer 18(1):196.

39. Cutress ML, Stewart GD, Wells-Cole S, Phipps S, Thomas BG, et al. (2012) Long-term endoscopic management of upper tract urothelial carcinoma: 20year single-centre experience. BJU Int 110(11): 16081617.

40. Jeldres C, Lughezzani G, Sun M, Isbarn H, Shariat SF, et al. (2010) Segmental ureterectomy can safely be performed in patients with transitional cell carcinoma of the ureter. J Urol 183(4): 1324-1329.

41. Lughezzani G, Jeldres C, Isbarn $H$, Sun M, Shariat SF, et al. (2009) Nephroureterectomy and segmental ureterectomy in the treatment of invasive upper tract urothelial carcinoma: a population-based study of 2299 patients. Eur J Cancer 45(18): 3291-3297.

42. Colin P, Ouzzane A, Pignot G, Ravier E, Crouzet S, et al. (2012) Comparison of oncological outcomes after segmental ureterectomy or radical nephroureterectomy in urothelial carcinomas of the upper urinary tract: results from a large French multicentre study. BJU Int 110(8): 1134-1141.

43. Robinson S, Parnham A and Motiwala H (2017) Open Distal Ureterectomy and Boari Flap Reconstruction for Distal Ureteric Transitional Cell Carcinoma. SM J Urol 3(3): 1035. 